\title{
COMPARATIVE STUDY OF 0.0625\% BUPIVACAINE WITH FENTANYL VERSUS 0.1\% ROPIVACAINE WITH FENTANYL AS CONTINUOUS EPIDURAL INFUSION IN LABOUR ANALGESIA
}

\author{
L. Raghavan', J. Revathy²
}

${ }_{1}^{1}$ Associate Professor, Department of Anaesthesiology, Chengalpattu Medical College.

2Professor, Department of Anaesthesiology, Chengalpattu Medical College.

\section{ABSTRACT}

\section{BACKGROUND}

We undertook this study to see whether ropivacaine offers any significant advantage over bupivacaine in our institutional practice with regards to obstetrical outcome and whether a changeover from bupivacaine to ropivacaine was warranted. This study compares the efficacy of Ropivacaine and Bupivacaine regarding pain relief, motor block and labour characteristics.

\section{AIM}

The objective of the current study is to compare the efficacy of equipotent doses of ropivacaine with fentanyl and bupivacaine with fentanyl as continuous infusion in labour epidural analgesia with respect to Quality of pain relief, Motor Block, Duration of labour, Mode of delivery - Spontaneous Vaginal/Assisted with forceps/Caesarean Section, Neonatal outcome - APGAR score, Complications if any.

\section{METHODS AND MATERIALS}

The study was a prospective randomized double blinded trial involving 60 parturients ( 30 in each group) attending the Dept. of Obstetrics and Gynaecology, Chengalpattu Medical College Hospital. Informed consent was obtained. Detailed history of the patient was collected. Routine investigations were done as per our hospital labour protocol. Patients fulfilling the inclusion criteria and who gave consent were then randomly allocated to one of the study groups on the basis of computerized randomized list.

\section{STATISTICAL ANALYSIS}

The statistical analysis was done using SPSS version 16 for windows. The profiles of the cases were compared with the treatment allocation in order to check if there was any significant difference. Chi-square test for association was used to compare categorical variables between treatment allocations.

\section{RESULTS}

The observations of this study show that pain relief offered by epidural ropivacaine is as good and effective as epidural bupivacaine. Also the duration of labour, mode of delivery, neonatal outcome and complications are comparable between the two groups.

\section{CONCLUSION}

Findings suggest that the use of epidural ropivacaine for labour analgesia had no added advantage, because highly diluted concentrations of bupivacaine plus opioids reduce the risk of cardiovascular toxicity and the degree of motor block are equally effective as ropivacaine in the concentrations used in our study, and are less expensive and easily available.

\section{KEYWORDS}

Epidural, Labour Analgesia, Bupivacaine, Bupivacaine.

HOW TO CITE THIS ARTICLE: Raghavan L, Revathy J. Comparative study of $0.0625 \%$ bupivacaine with fentanyl versus $0.1 \%$ ropivacaine with fentanyl as continuous epidural infusion in labour analgesia. J. Evolution Med. Dent. Sci. 2016;5(53):3474-3479, DOI: $10.14260 /$ jemds/2016/802

\section{INTRODUCTION}

Labour is one of the happiest as well as the most painful moments in a woman's life. It can lead to unpleasant experiences unless treated properly. Not every woman wants or needs analgesic intervention for delivery.

The ASA and ACOG have said that "Labour causes severe pain for many women. There are no other circumstances where it is considered acceptable for an individual to experience untreated severe pain, amenable to safe

Financial or Other, Competing Interest: None.

Submission 06-06-2016, Peer Review 15-06-2016,

Acceptance 18-06-2016, Published 01-07-2016.

Corresponding Author:

Dr. L. Raghavan,

A-40, Arcot Terrace

No.160-NSK Salai,

Vadapalani,

Chennai-600026.

E-mail: lraghavan63@gmail.com

DOI: $10.14260 /$ jemds $/ 2016 / 802$ intervention while under a physician's care. Pain management should be provided whenever medically indicated."

The first documented incident of pain relief during labour was for Fanny Longfellow in 1847 with ether. The second woman to become famous was Emma Darwin, wife of Charles Darwin, who was administered chloroform during labour. The third incident influenced the history of labour analgesia was the administrations of chloroform to Queen Victoria by Dr. John Snow for her $8^{\text {th }}$ confinement to deliver Prince Leopold on April 7, 1853.

From 1840 s to 1960 s, different methods of pain relief were tried. This included inhalational agents, systemic agents (Opioids, Ketamine, Twilight sleep (Morphine + scopolamine) and local blocks.

The ideal analgesic agent should be safe for both the women and newborn and minimal effects on the labour 
progression. The best technique should produce longer, consistent analgesia without foetal or maternal side effects.

There are various modalities available now commonly. This included pharmacologic and non-pharmacological methods.

Pharmacological methods include inhalational agents (Entonox, sevoflurane), systemic opioids (Morphine, fentanyl, remifentanil as PCEA). Both these agents produce analgesia, but not in a continuous and effective manner. They also have systemic side effects on both the mother and foetus. They may also interfere with the progress of labour.

Pharmacological methods also include regional anaesthesia. This in turn comprises both regional blocks and central neuraxial blocks. Though regional blocks give good pain relief, they are associated with technical difficulties as well. Paracervical plexus blocks are no longer used because of their association with a relatively high foetal bradycardia. Pudendal nerve blocks are mostly useful only in second stage of labour.

Central neuraxial analgesia is the gold standard technique for pain relief in labour. Central neuraxial analgesia includes both subarachnoid as well as epidural block.

Among these epidural blockade comes close to being the ideal analgesic technique in labour. It provides continuous analgesia for an unpredictable period of time and to convert analgesia to anaesthesia if an operative intervention becomes necessary.

Previously epidural injections of higher concentration of local anaesthetic combined with opioids were used. It was associated with significant motor blockade. Nowadays, less concentrations of local anaesthetics combined with opioids provides good analgesia with little motor blockade known as "walking epidural." The pain relief starts sooner and lasts longer than either drug alone. It allows both the drugs to be used in lower concentration, thereby reducing the risk of local anaesthetic systemic toxicity as well as opioids side effects.

Bupivacaine and Ropivacaine are commonly used for epidural analgesia in labour. Bupivacaine may increase the risk of motor blockade (Associated with maternal dissatisfaction and increased instrumental deliveries) and cardiac toxicity. Ropivacaine has the advantage of more sensory blockade, less motor blockade than bupivacaine and decreased risk of systemic toxicity. Diluted local anaesthetic solution combined with opioids decreases the incidence of motor block.

\section{METHODS AND MATERIALS}

After obtaining approval from the Hospital Ethical Committee, this study was conducted for a period of 4 months from January 2016 to April 2016. Sixty patients were randomly selected and divided into two groups of thirty each. Patient counseling was done and written informed consent obtained from the patients.

\section{Group B}

Bupivacaine $0.0625 \%$ with fentanyl $(2 \mu \mathrm{g} / \mathrm{mL})$.

\section{Group R}

Ropivacaine $0.1 \%$ with fentanyl ( $2 \mu \mathrm{g} / \mathrm{mL})$.

\section{Inclusion Criteria}

1. Normal singleton primiparous patients.

2. Age 18-35 years.
3. ASA status - I and II.

4. Patients in active labour with cervical dilatation - 3 or $4 \mathrm{~cm}$.

\section{Exclusion Criteria}

1. Contraindications to epidural block.

2. Pre-term pregnancy.

3. Multiple pregnancy.

4. Previous caesarean section.

5. Failed epidural.

\section{Materials Needed}

1. 18 G Tuohy needle.

2. $20 \mathrm{G}$ epidural catheter.

3. $2 \mathrm{cc}, 5 \mathrm{cc}, 10 \mathrm{cc}$ sterile syringes.

4. Hypodermic needles - 18G and 26G.

5. Bowl, Sponge holding forceps, Swabs, Chlorhexidine Solution.

6. Sterile gown, Gloves, Cap and Mask.

7. Tape for fixing catheter.

8. Local anaesthetic solution-2\% Lignocaine with adrenaline.

9. $0.5 \%$ Bupivacaine Vial, $0.2 \%$ Ropivacaine ampoule, Fentanyl - 100 ug.

10. Boyle's apparatus and oxygen cylinder.

11. Emergency kit with working laryngoscope, cuffed endotracheal tubes of appropriate size, airway, suction apparatus with suction catheter.

12. Emergency drugs like Inj. Adrenaline, Inj. Atropine, Inj. Thiopentone, Inj. Succinylcholine.

13. Monitor for continuous monitoring of non-invasive blood pressure, ECG, Respiratory rate, Oxygen saturation.

\section{METHODOLOGY}

The patient in right lateral position, under strict aseptic precautions, $20 \mathrm{G}$ epidural cannula inserted in the L3-L4 interspace using $18 \mathrm{G}$ Tuohy needle with loss of resistance technique. A test dose of local anaesthetic $(3 \mathrm{~mL}$ of $2 \%$ Lignocaine with 1:200000 Adrenaline) was injected via the catheter to rule out intravascular or intrathecal placement of catheter. If there were no signs of motor block (Intrathecal placement) or tachycardia and ST depression (intravascular placement) after 3 to 5 minutes, initial bolus dose of $10 \mathrm{~mL}$ of $0.2 \%$ ropivacaine (ropivacaine group) or $0.125 \%$ bupivacaine (bupivacaine group) were given. If then the patient is still uncomfortable (VAS >3) after 15 mins, an additional $5 \mathrm{~mL}$ of the local anaesthetic was given.

After the initial dose, analgesia was maintained using a continuous infusion of ropivacaine $0.1 \%$ with fentanyl $(2 \mu \mathrm{g} / \mathrm{mL}$ ) (Ropivacaine group) or bupivacaine $0.0625 \%$ with fentanyl (Bupivacaine group). Infusions were started at 8 $\mathrm{mL} / \mathrm{h}$ using a syringe pump. Further boluses of $5 \mathrm{~mL}$ of ropivacaine $0.2 \%$ or bupivacaine $0.125 \%$ were given for breakthrough pain. The total number of boluses required during the first and second stages of labour was recorded.

The study concluded at the time of vaginal delivery, assisted forceps or when the decision was made to perform a caesarean delivery. The catheter is used for epidural anaesthesia in case of caesarean delivery. Both the patient and the anaesthesiologist who gave analgesia were blinded to the study solutions. 
Various maternal parameters were continuously monitored and noted every 15 minutes in the first hour, every 30 minutes in the second hour and every hourly thereafter. Continuous foetal heart monitoring was also done.

\section{Parameters Monitored}

1. Maternal heart rate.

2. Maternal blood pressure.

3. Maternal oxygen saturation.

4. Foetal heart rate.

5. Pain relief using visual analog scale.

6. Motor block by modified Bromage score.

\section{Clinical Outcome Studied}

1. Pain relief.

2. Motor block.

3. Duration of labour.

4. Mode of delivery - Vaginal - Spontaneous/ Forceps/caesarean.

5. Patient satisfaction.

6. Neonatal outcome-APGAR score.

\section{OBSERVATION AND RESULTS}

Our study included 60 pregnant women. They were randomly allocated to either group R $0.125 \%$ bupivacaine with 2 $\mathrm{ug} / \mathrm{mL}$ fentanyl) or Group - $\mathrm{R}(0.1 \%$ ropivacaine with 2 $\mathrm{ug} / \mathrm{mL}$ fentanyl). The initial patient characteristics such as age, weight, height, patient ASA grade, vaginal dilatation, comorbid conditions of the patients were noted.

The outcomes measured were haemodynamics of the patient, pain score, bolus requirement, motor block, mode of delivery, duration of labour, neonatal outcome and complications if any.

\section{Patient Characteristics}

The distribution of patients was not statistically significant in respect to age, weight, height and ASA grading by student's T test.

\section{Age}

The mean age of women in Group B was 24.5+2.83 years and that of Group R was 24.6+2.37 ( $\mathrm{P}=0.92)$.

\section{Weight}

In Group B was $60.47+8.06 \mathrm{~kg}$ and that of those in Group $\mathrm{R}$ was $64.27+7.15 \mathrm{~kg}(\mathrm{P}=0.06)$.

\section{Height}

In Group B was $151.2+.11 \mathrm{~cm}$ and that of those in Group R was $152.43+4.30 \mathrm{~cm}(\mathrm{P}=0.26)$.

\section{ASA Grade}

Overall, out of the 60 pregnant women, 65 (92.9\%) had ASA grade I pregnancy, the rest $5(7.1 \%)$ had ASA grade II pregnancy $(p=0.643)$.

\section{Comorbid Conditions (Chi Square Test)}

Group B had one women (3.3\%) with GDM (Gestational Diabetes Mellitus) and two (6.7\%) had PIH (Pregnancy Induced Hypertension). In group R, two (6.7\%) women had PIH. Their distribution among groups was not statistically significant $(p=0.6)$.

\section{Vaginal Dilatation (Student's T Test)}

The Vaginal Dilatation in group B was $3.37+0.54 \mathrm{~cm}$ and in group $\mathrm{R}$ was $3.51+0.74 \mathrm{~cm}$. This variable did not have any statistically significant difference $(\mathrm{p}=0.206)$.

\section{Sensory Level (Chi Square Test)}

Out of 30 patients, 22 patients $(73.3 \%)$ in group B and 20 patients $(66.7 \%)$ in group R had T8 level; 5 patients $(16.7 \%)$ in both groups had T7 sensory level. Two patients $(6.7 \%)$ in group B and 4 patients (13.3\%) in group R had T9 sensory level. One patient in group B had T6 level and one patient in group R had T10 level. The sensory level had no statistical significant difference between the two groups $(p=0.5)$.

\section{Onset of Pain Relief (Student's T Test)}

The mean onset of pain relief in group B $(12.4+2.1 \mathrm{~min})$, though slightly less than in group $\mathrm{R}(13.4+1.7 \mathrm{~min})$. This variable does not have any statistical significant difference $(\mathrm{p}=0.06)$.

\section{OUTCOME MEASURED}

\section{Haemodynamics}

All the patients had their haemodynamics monitored continuously starting at baseline (Before epidural), 15 mins, 30 mins, 45 mins, 1, 1.5, 2, 3, 4, 5, 6, 7 hours. The minimum monitoring time was around $3 \mathrm{hrs}$. in both the groups. The following table will show the number of patients monitored over the time period of their labour.

\section{Pain Score (Visual Analog Scale) - Chi Square Test} There was a noticeable decrease in the pain levels immediately after bolus. The pain levels did not go above visual analog score of 3 during infusion in both the groups. Most of the increase in pain scores occurred during the second stage of labour. But the pain score variation did not have any statistical significance.

\begin{tabular}{|c|c|c|}
\hline Time & Chi Square & P value \\
\hline Baseline & 0.07 & 0.79 \\
\hline 15 mins. & 2.76 & 0.4 \\
\hline 30 mins. & 0.16 & 0.7 \\
\hline 45 mins. & 0.74 & 0.4 \\
\hline 1 hr. & 3.15 & 0.07 \\
\hline 1.5 hrs. & 0.7 & 0.3 \\
\hline 2 hrs. & 0.16 & 0.7 \\
\hline 3 hrs. & 1.02 & 0.7 \\
\hline 4 hrs. & 3.15 & 0.2 \\
\hline 5 hrs. & 4.94 & 0.08 \\
\hline 6 hrs. & 2.9 & 0.2 \\
\hline \multicolumn{3}{|c|}{ Table 1: Pain Score } \\
\hline
\end{tabular}

\section{Bolus Requirement}

5 women in both groups required boluses during their labour. The proportion of women requiring boluses was comparable in both the groups.

\section{Patient Satisfaction (Student's T Test)}

The overall patient satisfaction for the pain relief was graded as excellent, fair and unsatisfactory. Out of 30 patients in each group, 23 patients $(76.7 \%)$ in group B and 20 patients $(66.7 \%)$ in group $\mathrm{R}$ had "excellent" pain relief. Seven patients $(23.3 \%)$ in group B and 10 patients $(33.3 \%)$ in group $R$ graded as "Fair." None of the patients in both groups graded 
as "unsatisfactory." No statistical difference in patient satisfaction was noted between the groups $(p=0.3)$.

\section{Statistical Analysis}

The statistical analysis was done using SPSS (Statistical Package for Social Sciences) version 16 for windows. The profiles of the cases were compared with the treatment allocation in order to check if there was any significant difference. Descriptive statistics are presented as mean+SD. Component bar and line diagrams were drawn as and when required. Chi-square test for association was used to compare categorical variables between treatment allocations.

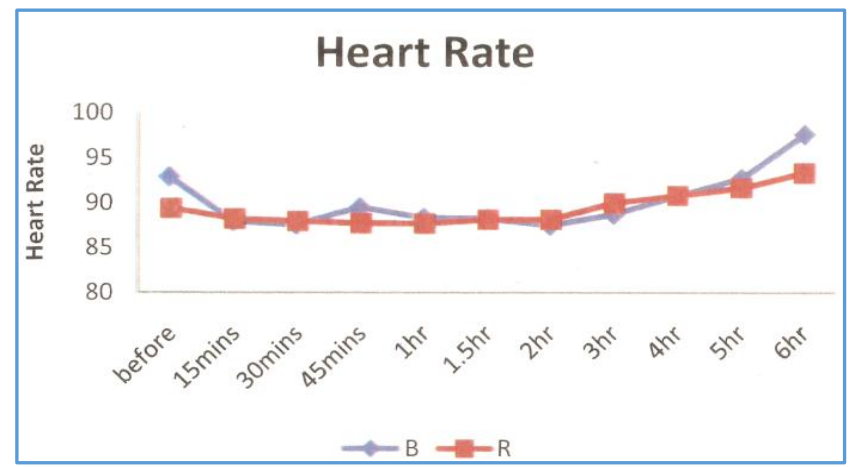

Fig. 1: Heart Rate

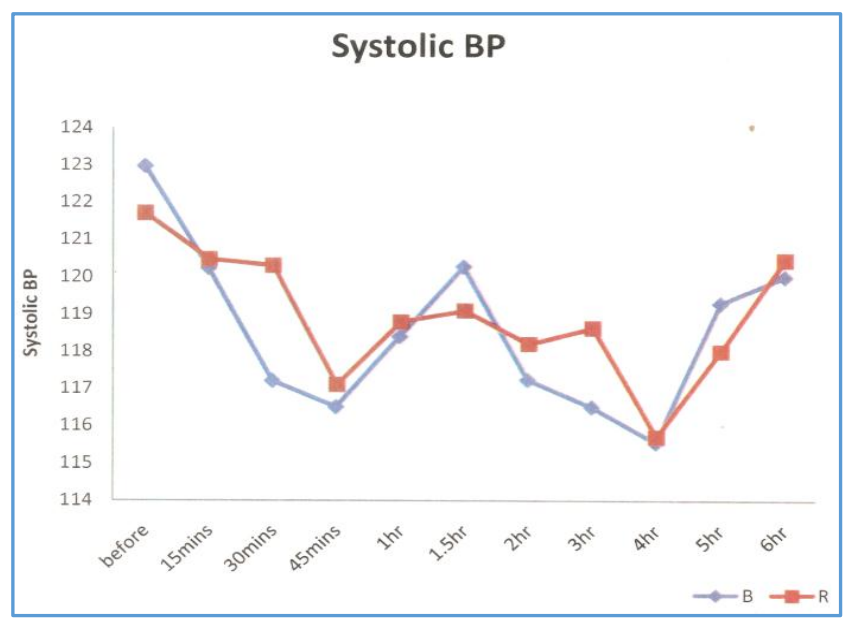

Fig. 2: Systolic Blood Pressure

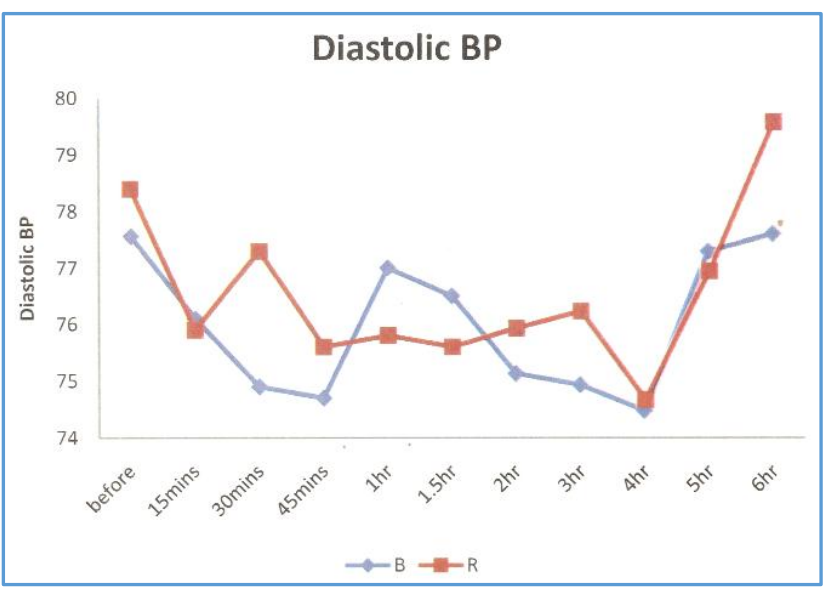

Fig. 3: Diastolic Blood Pressure

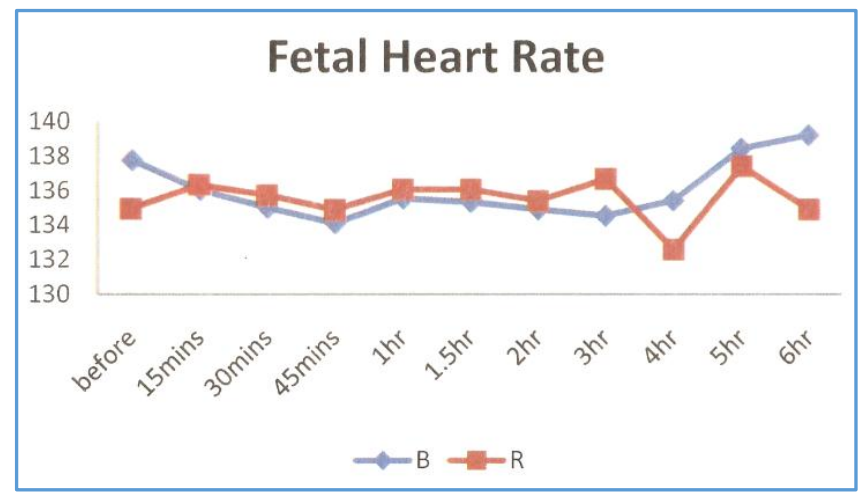

Fig. 4: Foetal Heart Rate

\section{DISCUSSION}

The recently published Cochrane review. ${ }^{1}$ on epidural versus non-epidural or no analgesia in labour has concluded that epidural offered better pain relief, a reduction in the need for additional pain relief, a reduced risk of acidosis and a reduced risk of naloxone administration.

Many studies state that the potency of ropivacaine is $60 \%$ as that of bupivacaine. ${ }^{2}$ There have been many studies, which compare equal concentrations of both drugs. ${ }^{3}$ (i.e. $0.125 \%$ bupivacaine vs. $0.125 \%$ ropivacaine). There have also been many studies, which state to have compared equipotent concentrations of both drugs (i.e. $0.1 \%$ bupivacaine vs $0.15 \%$ ropivacaine). Most of the studies have found that both drugs did not differ significantly except ropivacaine had less motor block on prolonged infusion.

The recommended dose of bupivacaine in labour epidural analgesia is $0.0625 \%-0.125 \%$ and that of ropivacaine is $0.08 \%-0.2 \%$ at the rate of $8-15 \mathrm{~mL} /$ hour. $^{4}$

Neuraxial local anaesthetics and opioids act synergistically to provide neuraxial analgesia. This combination decreases the MLAC of local anaesthetics used. We used fentanyl in a concentration of $2 \mu \mathrm{g} / \mathrm{mL}$, as it was used most commonly in previous studies.

In our study, we used initial bolus of $10 \mathrm{~mL} 0.125 \%$ bupivacaine and $0.2 \%$ ropivacaine and maintained with low concentration of equipotent doses of $0.0625 \%$ bupivacaine and $0.1 \%$ ropivacaine with fentanyl $2 \mu \mathrm{g} / \mathrm{mL}$ at a rate of 8 $\mathrm{mL} / \mathrm{hr}$ as continuous infusion.

The parturient were comparable in regards to age, weight, height, vaginal dilatation in both groups.

\section{Pain Relief}

Pain is a subjective phenomenon and it is difficult to measure. There are many different scales to measure pain; we used visual analog scale, because it is a widely used scoring system.

In our study, we found that the mean VAS score was around 7.5 in bupivacaine group and 7.6 in ropivacaine group. This has been reduced to 3.1 in bupivacaine group and 1.5 in ropivacaine group 15 mins after epidural and further reduced to very low levels in 30 mins. There was no clinically demonstrable difference in the onset of pain relief. The patient satisfaction was also comparable between the two groups.

\section{This was Consistent with the Results Obtained by}

Meister. 5 et al (2000) compared equal concentrations of $0.125 \%$ bupivacaine and $0.125 \%$ ropivacaine along with 
fentanyl in both groups. They found that mean VAS scores, which were around 9 in bupivacaine and 8 in ropivacaine, respectively came down to 0.4 and 0.3 post epidural.

Fernandez et al (2001) when they compared $0.0625 \%$ bupivacaine with fentanyl and $0.1 \%$ ropivacaine and fentanyl, there were no clinically demonstrable differences in the onset of pain relief. Patient satisfaction was also comparable in both groups.

\section{Motor Blockade}

When Halpern et al 2003 did a meta-analysis comparing ropivacaine and bupivacaine, he found that 19 out of 23 studies favoured ropivacaine to have minimal motor block and 5 of those studies were statistically significant.

The incidence of motor block was low in ropivacaine and also significantly lower than bupivacaine in many of the comparative studies (Campbell.6, Fischer. ${ }^{7}$ 2000, Meister 2000, 2000). In our study, there was no clinically demonstrable motor block in both groups. This may be because the concentration of the drugs used in my study was low.

\section{DURATION OF LABOUR}

\section{Duration of $1^{\text {st }}$ Stage of Labour}

A meta-analysis by Halpern et al (1988) concluded that epidural analgesia prolonged $1^{\text {st }}$ stage of labour by 42 minutes.

But other studies including the recent Cochrane review. ${ }^{1}$ comparing epidural and non-epidural methods of labour analgesia did not find any difference in the length of $1^{\text {st }}$ stage of labour.

In our study, the duration of active first stage of labour (3 $\mathrm{cm}-10 \mathrm{~cm}$ ) was $223.67+40.7$ minutes in bupivacaine group and $235+24.8$ minutes in the ropivacaine group. There was no statistically significant difference in the mean duration.

Many studies compared varying concentrations of bupivacaine with ropivacaine. They did not find any difference in the duration of $1^{\text {st }}$ stage of labour between bupivacaine and ropivacaine (Feranandez. ${ }^{8}$ 2001, Owen. ${ }^{9}$ 2002).

The results of our study correlate well with the above mentioned studies.

In contrast Lee.10 et al 2002 in their study compared found that the bupivacaine group had longer first stage of labour than ropivacaine group. However, they concluded that the difference may be of limited clinical significance.

\section{Duration of $2^{\text {nd }}$ Stage of Labour}

According to ACOG guidelines, second stage of labour is said to be prolonged when the duration was more than 3 hours for primipara and more than 2 hours for multipara with regional anaesthesia.

In our study, there was no difference in the duration of second stage of labour in both groups. The mean duration was 31.33 mins. in bupivacaine group and 32.5 mins. in ropivacaine group. This difference was not statistically significant.

This result coincides with,

A meta-analysis done by Halpern et al in 2003, which took into account 23 studies comparing ropivacaine and bupivacaine for labour epidural analgesia. They found that neither bupivacaine nor ropivacaine group had any difference in the duration of second stage of labour.

In contrast to some studies such as,

A meta-analysis done by Halpern. ${ }^{11}$ et al on 2400 parturients who received either epidural analgesia or parenteral opioids analgesia found that the second stage of labour was prolonged by 14 minutes.

A recent Cochrane review on epidural versus nonepidural or no analgesia in labour found that women who had epidural were more likely to have a longer second stage of labour.

\section{MODE OF DELIVERY}

\section{Instrumental Vaginal Delivery}

Leighton. ${ }^{12}$ et al 1988 in their meta-analysis found that women with epidural were twice as likely to have an instrumental vaginal delivery as compared to control groups. Cambic. ${ }^{13}$ and Wong 2010 in their review on labour analgesia and obstetric outcomes concluded that effective second stage analgesia might be associated with an increased rate of instrumental vaginal delivery.

In our study, we had an instrumental delivery rate of $13.3 \%$ in both groups. In majority of cases, maternal failure was the cause of instrumental delivery.

Our study results coincide with the study done by,

FineGold.14 et al in 2000, which used as similar concentration of drugs as our study. They had an instrumental vaginal delivery rate of $18 \%$ in ropivacaine group and $28 \%$ in bupivacaine. In both our studies though the instrumental delivery rates were less in ropivacaine, the differences were not statistically significant.

The meta-analysis of 23 studies comparing ropivacaine and bupivacaine in 2003 by Halpern et al also did not find any difference in the mode of delivery between the two drugs.

\section{Caesarean Delivery}

Epidural analgesia is not associated with an increased rate of caesarean delivery. This has been the conclusion of a metaanalysis by Halpern et al 1988 and the recent Cochrane review 2011 done on epidurals, non-epidurals and no analgesia in labour.

In our study, we had a caesarean delivery rate of $10 \%$ in bupivacaine and $13.3 \%$ in ropivacaine group. The differences were not statistically significant. The main reasons for the caesarean delivery among both groups were failure to progress, foetal distress due to cord around the neck and meconium stained liquor. These result correlates with the following studies.

Beilin. ${ }^{15}$ et al in 2007 compared ropivacaine with bupivacaine and their effect on outcome of delivery. Bupivacaine group had a caesarean rate of 33\% against a $30 \%$ rate in ropivacaine group.

The meta-analysis by Halpern et al 2003 also found no difference in caesarean delivery rates between ropivacaine and bupivacaine when used for labour epidural.

\section{Foetal and Neonatal Outcome}

The recent Cochrane review which compared epidural analgesia with other forms of analgesia including inhalational and intravenous (Mainly opioids) observed that there was 
less foetal acidosis and less naloxone administration in babies born to mothers having labour epidural analgesia.

In our study, the foetal heart rate during the process of labour analgesia was within normal limits. There was no incidence of post-epidural foetal bradycardia. The APGAR score was also not statistically significant.

Beilin. ${ }^{15}$ and Halpern in 2010 did a focused review with various studies that compared bupivacaine and ropivacaine and concluded that there was no evidence that neonatal outcome is adversely affected when ropivacaine or bupivacaine is used for labour analgesia.

Writer. ${ }^{16}$ et al found a difference in the neurologic and adaptive capacity score, favouring ropivacaine, at 24 hours after birth, but not 2 hours after birth. But recent evidence suggests that the neurologic and adaptive capacity score is unreliable. The incidence of low Apgar scores at 5 minutes is approximately $2 \%$ for both drugs. In addition, the umbilical artery and vein $\mathrm{PH}$ are well maintained regardless of which local anaesthetic is used. Also, the incidence of need for neonatal resuscitation is low and similar with both drugs.

\section{COMPLICATIONS}

No adverse complications were noted in both the groups.

\section{ACKNOWLEDGEMENT}

We are very grateful to the professors and assistant professors of the Department of Obstetrics and Gynaecology.

We are extremely thankful to the professors and the postgraduates of the Department of Anaesthesiology for their help in carrying out this study.

We are thankful to the Institutional Ethical Committee for their guidance and approval for this study. Last but not the least, we thank all our patients for willingly submitting themselves for this study.

We also wish to state that no financial or material support was obtained for this study.

\section{CONCLUSION}

Findings suggest that the use of epidural ropivacaine for labour analgesia had no added advantage, because highly diluted concentrations of bupivacaine plus an opioid reduce the risk of cardiovascular toxicity and the degree of motor block are equally effective as ropivacaine in the concentrations used in our study and are less expensive and easily available.

\section{REFERENCES}

1. Anim-Somuah M, Smyth R, Howell C. Epidural versus non-epidural or no analgesia in labour. Cochrane Database Syst Rev 2005;4:CD000331.

2. Capogna G, Celleno D, Fusco P, et al. Relative potencies of bupivacaine and ropivacaine for analgesia in labour. Br J Anaesth 1999;82(3):371-3.
3. Owen MD, D'Angelo R, Gerancher JC. $0.125 \%$ ropivacaine is similar to $0.125 \%$ bupivacaine for labour analgesia using patient controlled epidural infusion. Anaesth Analg 1998;86(3):527-31.

4. Wylie, Davidson C. Obstetric anaesthesia. In: Healy TJ, Knight PR, eds. A practice of anaesthesia. $7^{\text {th }}$ ed. London: Arnold Press, 2003.

5. Meister GC, D' Angelo R, Owen M, et al. A comparison of epidural analgesia with $0.125 \%$ ropivacaine with fentanyl versus $0.125 \%$ bupivacaine with fentanyl during labour. Anaesth Analg 2000;90(3):632-7.

6. Campbell DC, Zwack RM, Crone LA, et al. Ambulatory labour epidural analgesia: bupivacaine versus ropivacaine. Anaesth Analg 2000;90(6):1384-9.

7. Fischer C, Balnie P, Jaouen E, et al. Ropivacaine, $0.1 \%$, plus sufentanil, $0.5 \mathrm{ug} / \mathrm{mL}$, versus bupivacaine, $0.1 \%$, plus sufentanil, $0.5 \mathrm{ug} / \mathrm{mL}$, using patient-controlled epidural analgesia for labour: a double-blind comparison. Anaesthesiology 2000;92(6):1588-93.

8. Fernandez-Guisasola J, Serrano ML, Cobo B, et al. A comparison of $0.0625 \%$ bupivacaine with fentanyl and $0.1 \%$ ropivacaine with fentanyl for continuous epidural labour analgesia. Anaesth Analg 2001;92(5):1261-5.

9. Owen MD, Thomas JA, Smith T, et al. Ropivacaine $0.075 \%$ with fentanyl $2 \mathrm{ug} / \mathrm{mL}$ are equivalent for labour epidural analgesia. Anaesth Analg 2002;94(1):179-83.

10. Lee BB, Kee NWD, Lau WM, et al. Epidural infusions for labour analgesia: a comparison of $0.2 \%$ ropivacaine, $0.1 \%$ ropivacaine, and $0.1 \%$ ropivacaine with fentanyl. Reg Anaesth Pain Med 2002;27(1):31-6.

11. Halpern SH, Walsh V. Epidural ropivacaine versus bupivacaine for labour: a meta-analysis. Anaesth Analg 2003;96(5):1473-9.

12. Leighton BL, Halpern SH, Ohlsson A, et al. Effect of epidural vs parenteral opioid analgesia on the progress of labour: a meta-analysis. JAMA 1998;280(24):210510.

13. Cambic CR, Wong CA. Labour analgesia and obstetric outcomes. British Journal of Anaesthesia 2010;105(S1):i50-i60.

14. Finegold H, Mandell G, Ramanathan S. Comparison of ropivacaine $0 . \%$ fentanyl and bupivacaine $0.125 \%$ fentanyl infusions for epidural labour analgesia. Can J Anaesth 2000;47(8):740-5.

15. Beilin Y, Halpern S. Focused review: ropivacaine versus bupivacaine for epidural labour analgesia. Anaesth Analg 2010;111(2):482-7.

16. Writer WD, Stienstra R, Eddleston JM, et al. Neonatal outcome and mode of delivery after epidural analgesia for labour with ropivacaine and bupivacaine: a prospective meta-analysis. $\mathrm{Br} \mathrm{J}$ Anaesth 1998;81(5):713-7. 